\title{
Prevalence of Primary Headache Disease and Associated Factors with it among Rift Valley University Adama Campus Students, 2019
}

Daniel Gebretsadik Woldegiorgis ( $\boldsymbol{\alpha}$ danielt@arsiun.edu.et )

Arsi University https://orcid.org/0000-0002-8549-3961

Tadesse Seda Bedasa

None

Research article

Keywords: Headache, migraine, prevalence, tension-type headache, students

Posted Date: October 30th, 2020

DOI: https://doi.org/10.21203/rs.3.rs-97691/v1

License: (c) (i) This work is licensed under a Creative Commons Attribution 4.0 International License.

Read Full License 


\section{Abstract}

Background: Headache is a highly prevalent condition among University students than among other population groups but usually under-diagnosed and under-treated. Headache attacks lead to the loss of days of study and poor academic performance. However, the situation in Ethiopia is not well documented. Therefore, this research aimed to assess the prevalence of primary headache and associated factors among Rift Valley University Adama Campus Students.

Methodology: Participants were selected using stratified random sampling from three faculties of Rift Valley University, Adama. An interviewer-administered questionnaire developed by reviewing related literature and headache-attributed restriction, disability, social handicap, and impaired participation (HARDSHIP) questionnaire and used to collect the data. STATA 12 was employed for data cleaning and analysis. Variables with a P-value of 0.25 and below on the bivariate logistic regression were considered for Multivariate analysis. Finally, a P-value of $<0.05$ was considered as statistically significant.

Results: A total of 240 students participated in this research. The mean age of the students was $23.5 \pm$ 2.4 years, $57.5 \%$ of them were female, 85.4 single, and $67.50 \%$ of them were urban dwellers. Almost all $(97.9 \%)$ of the respondents experienced a headache in their lifetime and $61.3 \%$ within the last 30 days. Among those who experienced headache $69(28.75 \%)$ had a primary type of headache. Forty-one (17.1\%) of the respondent's fulfilled the criteria for tension-type headache, 28 (11.7\%) migraine, and 155 (64.58) had an unclassified type of headache. After controlling possible confounding effects of other covariates, age 23-28 year [AOR: $3.52,95 \% \mathrm{Cl}=1.69,7.23$ ], students from business faculty [AOR: $0.30,95 \% \mathrm{Cl}=0.11$, 0.79 ], being from urban areas [AOR: $2.13,95 \% \mathrm{Cl}=1.04,4.35$ ], had history of nausea and vomiting [AOR: 8.49, 95\% $\mathrm{Cl}=3.12,23.15$ ] and bothered by bright light [AOR: $2.15,95 \% \mathrm{Cl}=1.30,3.57]$ had a significant association with primary headache.

Conclusion: Headache is a common complaint among Rift Valley University Adama Campus students and it limits the daily activity of the majority of the sufferers. Students need proper education about treatment to ease their suffering and forestall complications.

\section{Background}

Headache is one of the most common neurological complaints encountered in clinical practice; most especially among the young population (1). It is one of the leading complaints seen in medical outpatient clinics and it is responsible for several visitations to the neurologist and general medical practitioners (2). It is one of the most common neurological disorders (2) and accounts for multiple visits to the general physician and neurologist. Its lifetime prevalence is quite high (82.7-93\%) in the general population (3). Primary headache disorders, including migraine, tension-type, and cluster, are considered as major global health problems due to their high prevalence, chronicness and their substantial disability burden upon the sufferers $(4,5)$. 
Migraine and tension-type headache (TTH) are the two most common types of headaches. Various studies have shown the prevalence of migraines to be $2.4 \%-6 \%$ in males and $3.6 \%-15 \%$ in females and that of a tension-type headache the corresponding figures were $11.1 \%-63 \%$ in males and $11.8 \%-86 \%$ in females $(3,6)$. Mostly migraine and tension-type headache $(\mathrm{TTH})$, have emerged as major global public health concerns, lead to widespread health loss, impaired quality of life, and much loss of productivity (5, $7,8)$. They often begin in adolescence and have a high risk of developing into a chronic condition and persisting into adulthood $(9,10)$. Few studies have been done on specific groups of the population like nurses and medical and university students which have found the prevalence of TTH to be between $12.2 \%$ and $22.64 \%$ and of migraine to be between $2.4 \%$ and $33.8 \%(11-14)$.

Headache disorders, especially in student populations are usually under-diagnosed and under-treated conditions, and thus the headache attacks lead to losing days of study and worse academic performance (15). Absenteeism from school due to headaches has affected students and their academic performance. A global study indicates that within 4 weeks, a fifth of pupils with headaches, lose at least one complete day from school; another fifth leave school early at least once, implying the loss of part of a day and almost half miss out on other school activities (16). Furthermore, students have difficulty in maintaining attention during lessons and completing homework $(11,17,18)$.

Several studies suggested different factors contributing to primary headaches. Among these sex being women to be significantly affected by headaches than men $(14,19-21)$, family history of headache was also found to be a common factor for headache in a study conducted among undergraduate Nigerian students (14), Brazilian undergraduate students (22) and study in Oman (11), consumptions of alcohol and smoking (23), stress and irregular sleep (24-26), sunshine and loud noise (27), lack of adequate vacation (28), low physical activity, and history of head trauma (29). In a study conducted in Northern India, Nausea/vomiting and scalp tenderness were the most common associated symptoms observed in students with recurrent headaches whereas migraineurs complained of photophobia/phonophobia along with nausea/vomiting, which is already documented associated symptoms confirming the diagnosis of migraine (30).

There is a scanty data on the prevalence of primary headaches in sub-Saharan Africa in general and Ethiopia in particular including in this study area. Therefore, this study is conducted to assess the prevalence of primary headache and associated factors among RVU Adama Campus students.

\section{Methodology}

\section{Study area}

Rift Valley University is a private higher learning institution that was established in October 2000 in Adama Town. It began to operate with 5 diploma programs of study, and about 154 evening students and five part-time academic staff. The first batch of students was graduated in August 2002. At present RVU 
Adama campus enrolled more than three thousand students in different fields both in Degree and Masters programs both in regular and extension.

\section{Study design and period}

An institution-based cross-sectional study was used to determine the prevalence of headache and associated factors among RVU Adama Campus students from October 7 to 14, 2019.

\section{Sample size determination}

The sample size calculation was done using single population proportion formula with the following assumption: $81.1 \%$ prevalence of headache in the last 12 months among Godar University Health Science students (28), a 5\% precision, $95 \%$ level of confidence, and $10 \%$ non-response rate. Samples of 258 students were required for this study

\section{Sampling procedure}

In this study, by considering faculty of study and year of enrolment stratified random sampling was used. After obtaining the verbal informed consent each of the students was randomly selected when they were attending class.

\section{Data collection}

The data collecting tool was checked and evaluated for its appropriateness by doing a pre-test on 20 extension students of RVU. A half-day training given for data collectors, the objectives of the study and the diagnostic criteria of the International Headache Society (IHS) (31) data was collected from the randomly selected students under the supervision of the principal investigators using English version structured questionnaire. The first part contains the sociodemographic characteristics of students. The second part of the questionnaire was about the presence of headaches, followed by questions specific for headache sufferers like the number of headache episodes per time and the impact of headache on the daily activity of students. The third parts of the questionnaire were about triggering factors of headache.

\section{Data processing and analysis}

After proper cleaning, cross-checking, and coding of data descriptive as well as inferential statistics of the study were analyzed by using STATA 12. Bivariate and multivariate logistic regression was used to identify factors associated with the prevalence of headache among students. The variables with a pvalue of less than 0.25 in the bivariate analysis were entered into the multivariate model using the enter regression method. Model fitness was checked using Hosmer and Lemeshow goodness of a fit test.

\section{Data quality control}

Beyond Pretesting the questionnaire and training of the data collectors, the data collection process was closely monitored and supervised by the principal investigators. The collected data were reviewed and checked for completeness before data entry and incomplete data were discarded. 


\section{Result}

\section{Socio-demographic characteristics}

A total of 240 students from the RVU Adama Campus participated in this study. The majority of the patients $57.5 \%$ were females, $50.4 \%$ of them were in the age group between 17 to 22 years with the mean (SD) $23.51 \pm 4.20$ years. More than two-thirds of the participants, $67.5 \% \%$ were from urban dwellers, $63.3 \%$ were from the Business and Social Science Department, the majority (85.4\%) of them were single or never married and $65.8 \%$ of them were attended for less than two years in the University (Table 1 ) 
Table 1

Socio-demographic characteristics of RVU Adama Campus students, 2019

\begin{tabular}{|lll|}
\hline Variable & Frequency & $\%$ \\
\hline Sex & & \\
Male & 102 & 42.5 \\
Female & 138 & 57.5 \\
\hline Age & & \\
17-22 & 121 & 50.4 \\
23-28 & 97 & 40.2 \\
29-34 & 15 & 6.5 \\
$\geq 35$ & 7 & 2.9 \\
\hline Place of birth & & \\
Urban & 162 & 67.5 \\
Rural & 78 & 32.5 \\
\hline Marital status & & \\
Married & 35 & 14.6 \\
Single & 205 & 85.4 \\
\hline Your faculty & & 18.3 \\
Health & 32 & 14.2 \\
Business & 152 & 63.3 \\
Technology & 54 & 22.5 \\
\hline Year of & & \\
education & 44.5 \\
First & 114 & \\
Second & 60 & \\
Third & 18 & \\
Fourth & 4 & \\
Fifth & & \\
\hline
\end{tabular}

\section{Headache characteristics}


Among respondents who had experienced headache about half $52.3 \%$ of them had unilateral, throbbing/pulsating, headache persists for hours (50.6\%), the headache was quite bad for them when occurs (53.6\%) and sometimes impaired their routine activities (53.2\%) (Table 2). 
Table 2

Characteristics of Headache among RVU Adama Campus

Students, $2019(n=235)$

\begin{tabular}{|lll|}
\hline Variable & Frequency & $\%$ \\
\hline Headache side & & \\
Unilateral & 123 & 52.3 \\
Top of head & 14 & 5.9 \\
Around the eyes & 27 & 11.6 \\
Front of head & 50 & 21.3 \\
Back of head/neck & 21 & 8.9 \\
How long this headache usually & & \\
last & 63 & 26.8 \\
For a few minutes & 119 & 50.6 \\
Stayed for hours & 50 & 21.3 \\
Stayed for days & 3 & 1.3 \\
Never goes away & & \\
\hline How bad this headache for you? & & 53.3 \\
Not much bad & 82 & 34.9 \\
Quite bad & 126 & 53.6 \\
Very bad & 27 & 11.5 \\
\hline Nature of headache & 33.3 \\
Throbbing/Pulsing & 125 \\
Achy & 21 & \\
Tight & 50.3 \\
Stabbing & 47.3 \\
Shooting & & \\
\hline Impairment of routine activities & & \\
No impairment & & \\
Sometimes impaired & & \\
Complete impairment & & \\
\hline
\end{tabular}




\section{Associated symptoms and triggering factors}

Among 235 respondents who experienced headaches only $12.8 \%$ had nausea and/or vomiting and only $27.3 \%$ of them received treatment for their headache. Concerning the triggering factors for their headache about half $(48.9 \%)$ of them reported exercise, $3.8 \%$ flashing light, and $2.9 \%$ due to noise. A family history of similar headaches was present in $32.9 \%$ ) of students (Table 3 ).

Table 3

commonly associated symptoms and triggering factors for headache RVU Adama Campus, $2019(n=235)$

\begin{tabular}{|lll|}
\hline Variable & Frequency & $\%$ \\
\hline Presence of nausea/ vomiting & & \\
No & 205 & 87.2 \\
Yes & 30 & 12.8 \\
\hline $\begin{array}{l}\text { Ever take a drug to treat their } \\
\text { headache }\end{array}$ & 171 & 72.8 \\
No & 64 & 27.2 \\
Yes & & \\
\hline Exercise Triggering your headache & & \\
No & 120 & 51.1 \\
Yes & 115 & 48.9 \\
Flashlight as trigger & & \\
No & 113 & 48.1 \\
Not sure & 113 & 48.1 \\
Yes & 9 & 3.8 \\
\hline Noise as trigger & & \\
No & 79.9 \\
Not sure & 71 & 32.8 \\
Yes & 751 & 64.3 \\
Family History & & \\
Yes & & \\
No & & \\
\hline
\end{tabular}


Almost all (97.9\%) of the respondents reported ever had any type of headache. The 1-year headache prevalence was $84.2 \%(n=240)$ and $61.3 \%$ of them had a headache in the last 30 days. Among those who experienced headache $69(28.8 \%)$ had a primary type of headache. Forty-one $(17.5 \%)$ of the respondent's fulfilled the criteria for tension-type headache, 28 (11.9\%) migraine, and 155 (65.9) had an unclassified type of headache.

\section{Factors associated with headache}

In bivariate analysis Age, place of birth, faculty in which they belong, respondents who had impaired daily activities, bothered by flashlight/daylight, noise, and reported nausea and or vomiting had a significant association with a primary headache at a $P$. value of 0.25 . After controlling possible confounding effects of other covariates four factors remained as significant independent predictors of primary headache in multiple logistic regression adjustment: Age, faculty in which they belong, their place of birth, had nausea or vomiting, and bothered by flashlight had a significant association with primary headache (Table 4).

After controlling possible confounding effects of other covariates, respondents with the age group of 2328 year 3.5 times more likely to have primary headache compared with the age group of 17-22 years [AOR: $3.52,95 \% \mathrm{Cl}=1.69,7.23$ ], students from business faculty were $70 \%$ less likely to develop primary headache compared with health faculty respondents [AOR: $0.30,95 \% \mathrm{Cl}=0.11,0.79$ ], respondents from urban areas were 2 times more likely to develop primary headache compared with rural dwellers [AOR: $2.13,95 \% \mathrm{Cl}=1.04,4.35]$, respondents who had a history of nausea and vomiting 8.5 times more likely to have primary headache compared with no nausea and vomiting [AOR: $8.49,95 \% \mathrm{Cl}=3.12,23.15]$ and respondents who were bothered by flashlight 11.4 times more likely to have primary headache compared with who do not bother by flashlight [AOR:11.4, 95\% Cl=1.72, 75.9] had a significant association with primary headache (Table 4). 
Table 4

Factors associated with primary headache RVU Adama Campus students, 2019

\begin{tabular}{|c|c|c|c|c|c|}
\hline \multirow[t]{2}{*}{ Variable } & \multicolumn{2}{|c|}{ Headache } & \multirow[t]{2}{*}{ COR $(95 \% \mathrm{Cl})$} & \multirow[t]{2}{*}{ AOR $(95 \% \mathrm{Cl})$} & \multirow[t]{2}{*}{ P. Value } \\
\hline & Yes & No & & & \\
\hline \multicolumn{6}{|l|}{ Age } \\
\hline $17-22$ & 23 & 98 & 1 & 1 & \\
\hline $23-28$ & 10 & 57 & $2.99(1.62,5.49)$ & $3.52(1.69,7.29)$ * & 0.001 \\
\hline $29-34$ & 4 & 11 & $1.55(0.45,5.31)$ & $0.67(0.13,3.39)$ & 0.629 \\
\hline$\geq 35$ & 2 & 5 & $1.07(0.31,9.34)$ & $2.26(0.32,16.16)$ & 0.415 \\
\hline \multicolumn{6}{|l|}{ Any treatment } \\
\hline Yes & 27 & 37 & 1 & 1 & \\
\hline No & 42 & 129 & $2.24(1.22,4.11)$ & $1.59(0.74,3.45)$ & 0.233 \\
\hline \multicolumn{6}{|l|}{ Place of birth } \\
\hline Rural & 28 & 50 & 1 & 1 & \\
\hline Urban & 41 & 121 & $1.65(0.92,2.95)$ & $2.13(1.04,4.36)$ * & 0.039 \\
\hline \multicolumn{6}{|l|}{ Faculty } \\
\hline Health & 18 & 16 & 1 & 1 & \\
\hline Business \& Econ. & 39 & 113 & $0.31(0.14,0.66)$ & $0.30(0.11,0.79)$ * & 0.015 \\
\hline Technology & 12 & 42 & $0.25(0.10,0.64)$ & $0.41(0.14,1.26)$ & 0.119 \\
\hline \multicolumn{6}{|l|}{ Family History } \\
\hline No & 40 & 121 & 1 & 1 & \\
\hline Yes & 29 & 50 & $1.75(0.98,3.14)$ & $1.78(0.86,3.72)$ & 0.122 \\
\hline \multicolumn{6}{|l|}{ Nausea/Vomiting } \\
\hline Yes & 5 & 25 & $\begin{array}{l}6.36(2.79 \\
14.51)\end{array}$ & $8.49(3.12,23.15)$ & 0.0001 \\
\hline No & 36 & 169 & 1 & 1 & \\
\hline \multicolumn{6}{|l|}{$\begin{array}{l}\text { Effects on daily } \\
\text { activity }\end{array}$} \\
\hline NO & 40 & 85 & $1.71(0.95,3.10)$ & $0.51(0.82,2.37)$ & 0.182 \\
\hline Yes & 14 & 19 & $\begin{array}{l}12.3(2.41 \\
63.07)\end{array}$ & $3.14(.99,9.99)$ & 0.050 \\
\hline
\end{tabular}




\begin{tabular}{|c|c|c|c|c|c|}
\hline \multirow[t]{2}{*}{ Variable } & \multicolumn{2}{|c|}{ Headache } & \multirow[t]{2}{*}{ COR $(95 \% \mathrm{Cl})$} & \multirow[t]{2}{*}{ AOR $(95 \% \mathrm{Cl})$} & \multirow[t]{2}{*}{ P. Value } \\
\hline & Yes & No & & & \\
\hline \multicolumn{6}{|c|}{ Affected by flashlight } \\
\hline Yes & 7 & 2 & \multirow{3}{*}{$\begin{array}{l}12.32(2.41 \\
63.1) \\
1.71(0.95,3.10)\end{array}$} & $11.4(1.72,75.9)$ * & 0.012 \\
\hline Not sure & 37 & 76 & & $2.00(0.97,4.14)$ & 0.062 \\
\hline No & 25 & 88 & & 1 & \\
\hline
\end{tabular}

\section{Discussion}

Our study results showed the prevalence of lifetime headache and headache in the last 12 months was $97.9 \% 84.2 \%$, respectively. Which is higher than a study conducted among University of Gondar students, 81.11 and $67.22 \%$ respectively (32), in dental students of a tertiary care teaching dental hospital in Northern India, 63.9\% (30) and Pharmacy Students, Al Ain University, Abu Dhabi which was 82.6\% (33).

Among those experienced headaches in the last 12 months, only $28.8 \%$ (95\% Cl: $22.9,34.6)$ fulfilled the criteria of primary headache. This finding is similar to previously done researches in Addis Ababa among the Local community (34). However, this value is much lower than to the current global prevalence of $47 \%$ (35), Ojini et al. (14) reported $46 \%$ at a teaching hospital, Tertiary Health Facility in Lagos, Nigeria $39.3 \%$ (36), and a much higher prevalence of $74.5 \%$ had been documented among Brazilian undergraduates (22). While our finding was higher than a study conducted by Takele et. Al. (37) reported $16.4 \%$ among textile workers. The possible difference could be due to the study design and small population sizes in this study and cultural and environmental differences with the present study

The prevalence of the subtypes of headache was also noted and $17.1 \%$ with $95 \% \mathrm{Cl}(12.5,22.1)$, of them had TTH and $11.9 \%$ with $95 \% \mathrm{Cl}(7.5,15.8)$ of them had a migraine. This finding is similar to a study conducted in Addis Ababa by Mihila et. Al. $17.7 \%$ and $20.6 \%$ for migraine and THA respectively (38). But lower compared with a study conducted in Egypt $24.5 \%$ of them had TTH and $17.3 \%$ migraine (39), In Euro-light Project $(40,41)$, the mean prevalence of migraine in Europe was $14.7 \%$, while the overall prevalence of TTH was $62.6 \%$. In Georgia, the prevalence was $37.3 \%$ for TTH and $15.6 \%$ for migraine (42). This could be attributed to different methodologies and cultural diversity.

Our study documented a prevalence rate of migraines was $11.9 \%$ which is similar to a study in Benin among University students $11.3 \%$ (43), $12.4 \%$ among Turkey students (44), and $12.2 \%$ among students in Oman (11). But a considerably high compared to 'Ojini' $6.4 \%$ (14) and previous community-based studies in Ethiopia, 3-10\% $(25,34)$. However, the findings of this study were very low compared with a study among Kuwaitis medical students $27.9 \%$ (45) and the study of Florianopolis in Brazil, which was $22.1 \%$ (46). The difference in the prevalence can be attributed to the racial, environmental, nutritional, psychological, and social factors of a particular population contributing to the headache. The other 
explanation could be due to the rigorous and strenuous medical program could account for the higher prevalence of headaches among medical students.

The prevalence rate of TTH in our study was $17.1 \%$. This finding is much lower than the $47.7 \%$ documented in Zimbabwe (47), 25.5\% by Quesada-V'azquez et al. in Cuba (48), and Russell reported $86 \%$ (49). There has been wide variations and differences in the epidemiology of TTH across different cultures (35). These variations may result from differences in study design, study population, inclusion or exclusion of cases of infrequent episodic TTH, and overlap with probable migraine, cultural and environmental differences, or even genetic factors (50).

Although, sex has no significant association with primary headache in this research the prevalence of primary headache was a little bit higher in women compared with men as has been previously reported (19-21). This has been attributed to the effect of female sex hormones specifically estrogen, genetics, and differences in response to stress and pain perception or psychological burden on females.

The majority of respondents with primary headache in this study was with the age group of 23 and 28 years. This age group has a significant association with primary headaches. It is consistent with the findings in the literature that locate the maximum of the migraine prevalence is at a younger age (23). This may be explained by the fact that $90.8 \%$ of surveyed students are 16 to 29 years old.

The finding of this research the prevalence of primary headache was high among urban dwellers compared with rural and showed a significant association between respondents from urban and primary headaches. This is supported by a study conducted in Ethiopia in $2003 \& 2008(25,37)$. This might be due to the magico-religious perception of diseases and opting for traditional healing in rural communities may hinder the reporting of headaches. It is also the rural people who have a greater tolerance for pain.

The most common trigger factor for headache in this study was the presence of nausea and vomiting and sunshine or flashlight but different kinds of the literature indicated stress and lack of sleep in nonmedical students were stress and loud noise $(24-27,30)$.

\section{Limitation of the study}

The limitations of this study included sample size, in terms of both the students who were participated and the facilities that were used, which thereby limited the general applicability of the results. All data is based on self-reporting hence the study might be affected by reporting bias. Also, the study is prone to recall bias since most of the questions require recalling past experiences.

\section{Conclusion}

Headache is a common complaint among Rift Valley University Adama Campus students. The lifetime prevalence of any headache was $97.9 \%$ and $28.8 \%$ of them fulfilled the criteria of primary headache. Age, faculty in which they belong, their place of birth, had nausea or vomiting, and bothered by flashlight had a 
significant association with primary headache. Students need proper education and support about treatment to ease their suffering and forestall complications.

\section{Abbreviations}

HARDSHIP: Headache-Attributed Restriction, Disability, Social Handicap, and Impaired Participation; HIS: International Headache Society; IRB: Institute Review Board; RVU: Rift Valley University; SD: Standard Deviation; TTH: Tension-Type Headache

\section{Declarations}

\section{Availability of supporting data}

The datasets generated and/or analyzed during the current study are not publicly available due to some privacy reasons, but part of the raw data set will be available from the corresponding author upon reasonable request.

\section{Ethical Approval}

An ethical approval letter was obtained from the institutional review board (IRB) of RVU. Each study participant was adequately informed about the purpose, method, anticipated benefit, and risk of the study by the data collectors. Verbal informed consent was obtained from study participants and anonymity was maintained to ensure confidentiality. The respondents' right to refuse or withdraw from participating in the interview was fully maintained and the information provided by each respondent kept strictly confidential.

\section{Consent}

The data collectors read and explain the consent form until the respondents understood all and once willing to participate the data collector sing for reading and asking consent before an interview

\section{Funding}

The authors received no financial support for the research, authorship, and/or publication of this article

\section{Conflicts of Interest}

The authors declare that they have no conflicts of interest.

\section{Author Contributions}

Daniel G/Tsadik were responsible for review of the literature, conceptualization, methodology, investigation, supervision for project administration, data management, formal analysis, original draft preparation and for writing. 
Tadesse Seda contributed to review, validation of the questionnaire, assisting in data analysis, revising the article and gave final approval of the version to be published, and also agree to be accountable for all aspects of the work

\section{Acknowledgments}

The authors would like to thank Rift Valley University Adama Campus Management for their support they made to realize this research, data collectors, and all participants for their enthusiastic participation.

\section{References}

1. Nedaa Talee Al-Jabry AZA, Abrar Nasser Maqsud, et al. Prevalence and Risk Factors of Tension Headache among 3rd Year Female Medical Students at Taibah University in Saudi Arabia. International Journal of Academic Scientific Research. 2015;3(4):46-53.

2. Andlin_Sobocki p JB, Wittchen HU, Olesen J. Cost of disorders of the brain in Europe. Eur J Neurology. 2005;12 (1):1-27

3. Ho KH OB. A Community-based study of headache diagnosis and prevalence in Singapore. Cephalalgia 2003;23(1):6-13.

4. Iliopoulos P DD, Kerezoudi E, Limpitaki G, Xifaras M, Skiada D et al. Trigger factors in primary headaches subtypes: a cross-sectional study from a tertiary center in Greece. BMC Res Notes. 2015;8(393):1-10.

5. Steiner TJ BG, Jensen RH, Katsarava Z, Stovner LJ, Martelletti P. Headache disorders are the third cause of disability worldwide. J Headache Pain. 2015;16(58).

6. Aurangzeb S TM, Gul A, et al. Frequency of various types of headaches in postgraduate medical students of a tertiary care hospital. Pak J Neurol Sci. 2008;3(1):1-5.

7. Stovner L HK, Jensen R, Katsarava Z, Lipton R, Scher A et al The global burden of headache: a documentation of headache prevalence and disability worldwide. Cephalalgia 2007;27(3):193-210.

8. Headache GBoD. Global, regional, and national burden of migraine and tension-type headache, 19902016: a systematic analysis for the global burden of disease study 2016. Lancet Neurol. 2018;17(11)::954-76.

9. Kernick D RD, Campbell JL. Impact of headache on young people in a school population. $\mathrm{Br} \mathrm{J}$ Gen Pract. 2009;59:678-81.

10. Victor TW HX, Campbell JC, Buse DC, Lipton RB. Migraine prevalence by age and sex in the United States: A life-span study. Cephalalgia 2010;30:1065-72.

11. Deleu D KM, Humaidan H, Al Mantheri Z, Al Hashemi S. Prevalence and clinical characteristics of headache in medical students in Oman. Headache 2001(41):798-804.

12. Ibrahim NK AA, Alhazmi AM, et al. Prevalence, predictors and triggers of migraine headache among medical students and interns at King Abdulaziz University, Jeddah, Saudi Arabia. Pak J Med Sci 2017;33(2):270-5. 
13. Kurt S KY. Epidemiological and clinical characteristics of headache in university students. Clin Neurol Neurosurg. 2008;110(1):46-50.

14. Ojini FI ON, Danesi MA. Prevalence and clinical characteristics of headache in medical students of the University of Lagos, Nigeria. Cephalalgia. 2009;29:472-7.

15. Mitsikostas DD GS, Thomas A, Kalfakis N, Illias A, Papageorgiou C An epidemiological study of headaches among medical students in Athens. Headache. 1996;36:561-4

16. C. Wb-BI. Epidemiology of migraine and headache in children and adolescents. Curr Pain Headache Rep. 2013;17(341).

17. K BMN. Prevalence and characteristics of migraine in medical students and its impact on their daily activities. Annals of Indian Academy of Neurology. 2013;16 (2):221-5.

18. Smitherman TA MM, Buchanan EM. The negative impact of episodic migraine on a university population: Quality of life, functional impairment, and comorbid psychiatric symptoms. Headache 2011;51:581-9

19. E. A. MacGregor JDR, and T. Kurth. Sex-related differences in epidemiological and clinic-based headache studies. Headache. 2011;51(6):843-59.

20. Leonardi M RA. The burden of migraine: International perspectives. Neurol Sci 2013;34 (1):117-8.

21. Lopez-Mesonero L MS, Parra P, GamezLeyva G, Munoz P, Pascual J. Smoking as a precipitating factor for migraine: a survey in medical students. J Headache Pain 2009;10:101-3.

22. Falavigna A TA, Velho MC, Vedana VM, Silva RC, Mazzocchin T, et. al. Prevalence and impact of headache in undergraduate students in southern Brazil. Arq Neuropsiquiatr. 2010;68:873-7.

23. Lipton RB SA, Kolodner K, Liberman J, Steiner TJ, Stewart W-F. Migraine in the United States: Epidemiology and patterns of health care use. Neurology. 2002;58 885-94.

24. Nikiforow R HE. An epidemiological study of headache in an urban and rural population in Northern Finland. Headache 1998;18:137-45.

25. Teklehymanot R SB, Forsgen L, Ekbom K, Ekstedt J Migraine, chronic tension-type and cluster headache in Ethiopian rural community. Cephalalgia 2002;15(6):482-8.

26. Zivadino R WK, Sepic-Grahovac D, Jurjevic A, Bucuk M, BrnabicRazmilic 0 et al Migraine and tensiontype headache in Croatia. A population-based survey of precipitating factors. Cephalalgia 2003;25(3):336-43.

27. Ruchika T. SKB, Jayantee K. \& Usha K. M., Frequency and pattern of headache in medical residents and non-medical students in a tertiary care teaching hospital in North India J Evid Based Med Healthc. 2018 5(8).

28. Eshetie M. B. ZA, Mohammedbrhan A., Abebe B., Betelhem S. \& Fitsum S. T. Management of headache and associated factors among undergraduate medicine and health science students of the University of Gondar, North West Ethiopia The Journal of Headache and Pain. 2016;17(56).

29. Elena R. Lebedeva NRK, Denis V. Gilev \& Jes Olesen. Factors Associated With Primary Headache According To Diagnosis, Sex, and Social Group. Headache. 2016;56:341-56. 
30. Ruchika Nandha MKC. Prevalence and clinical characteristics of headache in dental students of a tertiary care teaching dental hospital in Northern India International Journal of Basic \& Clinical Pharmacology 2013;2(1):51-5.

31. Society HCCotIH. The International Classification of Headache Disorders. Cephalalgia 2013;33:629808.

32. Eshetie Melese Birru ZA, Mohammedbrhan Abdelwuhab, Abebe Basazn, Betelhem Sirak and Fitsum Sebsibe Teni. Management of headache and associated factors among undergraduate medicine and health science students of the University of Gondar, North West Ethiopia. The Journal of Headache and Pain. 2016;17(56):1-9.

33. Mohammad F. Bostanudin SAAaTSF. Epidemiology of Headache Disorders among Pharmacy Students. American Journal of Epidemiology \& Public Health. 2020;4(1):1-5.

34. Alemayehu GMS. Prevalence and burden of primary headache disorders among a local community in Addis Ababa, Ethiopia. The Journal of Headache \& Pain. 2013;14(30).

35. L. J. Stovner KH, R. Jensen et al. The global burden of headache: a documentation of headache prevalence and disability worldwide. Cephalalgia. 2007;27(3):193-210.

36. Olajumoke Oshinaike 00, Njideka Okubadejo, Olaitan Ojelabi, and Akinola Dada Primary Headache Disorders at a Tertiary Health Facility in Lagos, Nigeria: Prevalence and Consultation Patterns. BioMed Research International. 2014;2014:1-5.

37. Getahun Mengistu Takele RTHPM. Prevalence and burden of primary headache in Akaki textile mill workers, Ethiopia. J Headache Pain 2008;9:119-28

38. Mihila Zebenigus RT-H, Dawit K. Worku, Hallie Thomas \& Timothy J. Steiner. The prevalence of primary Headache disorders in Ethiopia. The Journal of Headache \& Pain. 2016;17(110).

39. Naglaa A. El-Sherbiny MM, Nevin M. Shalaby, and Hatem S. Shehata. Prevalence of primary headache disorders in Fayoum Governorate, Egypt The Journal of Headache \& Pain. 2015;16(85).

40. Stovner LJ AC. Prevalence of headache in Europe: a review for the Eurolight project. J Headache Pain. 2010;11:289-99

41. Steiner TJ SL, Katsarava Z, Lainez JM, Lampl C, Lanteri-Minet M et al. The impact of headache in Europe: principal results of the Eurolight project. J Headache Pain 2014;15:31-41.

42. Katsarava Z DA, Kukava M, Mirvelashvili E, Djibouti M, Janelidze M et al. Lifting the burden: the global campaign to reduce the burden of headache worldwide and the Russian linguistic subcommittee of the international headache society. Primary headache disorders in the Republic of Georgia: prevalence and risk factors. Neurology 2009;73:1796-803

43. Thierry Adoukonou DH, Judith Kankouan, et. al Migraine Among University Students in Cotonou Headache. 2009 49:887-93.

44. Demirkirkan MK EH, Boluk A. Tohoku. Prevalence and clinical characteristics of migraine in university students in Turkey. J Exp Med. 2006;208:87-92. 
45. Al-Hashel JY AS, Alroughani R, Goadsby PJ. Migraine among medical students at Kuwait University. Journal of Headache Pain. 2014;15(26).

46. Queiroz LP BL, Blank N. An epidemiological study of headache in Florianopolis, Brazil. Cephalalgia 2005;26:122- 7

47. A.J.Quesada-V'azquezandN.Rodr'ıguez-Santana. The prevalence of primary headaches in the working population at a psychiatric hospital in Zimbabwe. Revista de Neurologia. 2006;43(3):129-31.

48. A. J. Quesada-Vazquez LJC-M, A. 'AlvarezAliaga, and E. R. Traba-Tamayo. Prevalence of primary headachesinaruralpopulationinCuba. Revista de Neurologia. 2009;49(3):131-5.

49. M.B.Russell NL, J. `Saltyte-Benth, and K.Fenger. Tension-type headache in adolescents and adults: a population-based study of 33,764 twins. European Journal of Epidemiology. 2006;21(2):153-60.

50. Sahler K. Epidemiology and cultural differences in tension-type headache. Current Pain and Headache Reports. 2012;16(6):525-32.

\section{Figures}

\section{Types of headache among RVU Adamam campus students}

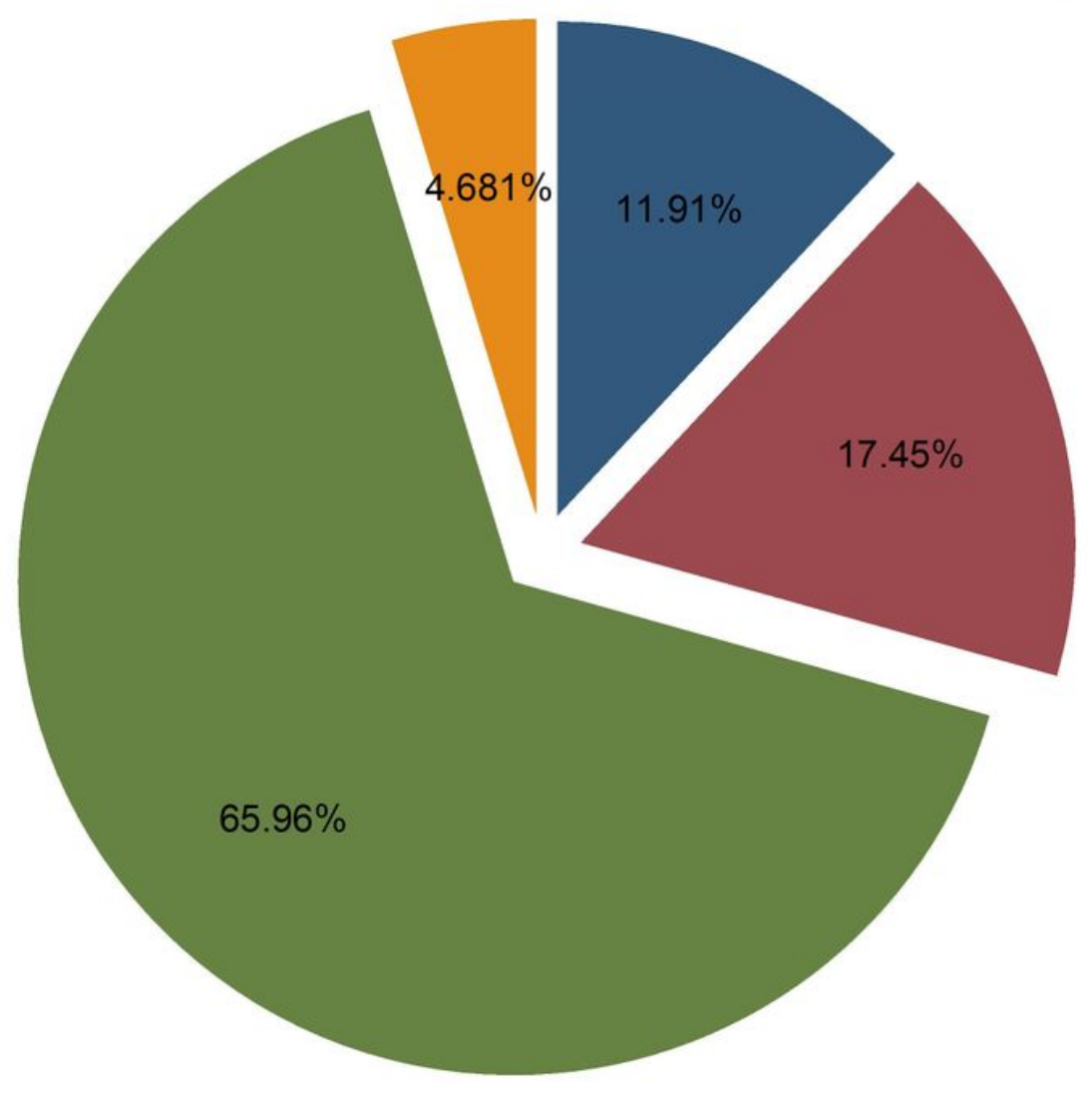


Percentage of headache type or diagnoses in RVU Adama Campus students, 2019

\section{Supplementary Files}

This is a list of supplementary files associated with this preprint. Click to download.

- Headacherevised.dta 